\title{
EFEITO DO RALEIO E DO ANELAMENTO DO TRONCO NO CRESCIMENTO, PRODUÇÃO E QUALIDADE DA AMEIXEIRA JAPONESA ${ }^{1}$
}

\author{
LUCIANO LARRUSCAHIM HAMILTON ILHA², GILMAR ARDUINO BETTIO MARODIN³, \\ EDUARDO SEIBERT ${ }^{4}$ e CARLOS IGUASSÚ NOGUEIRA BARRADAS ${ }^{5}$
}

\begin{abstract}
RESUMO - Na produção de ameixas (Prunus salicina Lindley) para consumo in natura, o tamanho do fruto é um dos aspectos mais valorizados. O raleio de frutos é tradicionalmente utilizado para obter, entre outros efeitos, a melhoria do tamanho dos frutos remanescentes. Uma antiga prática, que está recebendo renovada atenção, é o anelamento, que em muitas situações pode aumentar o tamanho dos frutos e antecipar a colheita. Este trabalho avaliou os efeitos do raleio manual de frutos em intensidades de $0,25,50$ e $75 \%$, associado ou não ao anelamento do tronco (4 mm de largura), sobre o crescimento, a produção e a qualidade da ameixeira cv. Amarelinha. O experimento foi conduzido na Estação Experimental Agronômica da Universidade Federal do Rio Grande do Sul (EEA/UFRGS) no ciclo 1995/96. O raleio foi realizado em 16/10/95, 36 dias após a plena floração, e o anelamento, sete dias após o raleio. O raleio reduziu a produção proporcionalmente à intensidade de raleio aplicada. O anelamento antecipou a colheita, diminuiu a firmeza e a acidez titulável, e aumentou a relação sólidos solúveis totais/acidez titulável dos frutos; mas diminuiu o vigor e o crescimento das plantas. Nenhum dos tratamentos alterou significativamente o peso médio dos frutos.
\end{abstract}

Termos para indexação: crescimento vegetativo, peso médio do fruto, precocidade, vigor.

\section{EFFECT OF THINNING AND OF TRUNK GIRDLING ON GROWTH, PRODUCTION AND QUALITY OF JAPANESE PLUMS}

\begin{abstract}
In the production of plums (Prunus salicina Lindley) for in natura consumption the fruit size is a very important feature. Fruit thinning is traditionally used to increase fruit size. Girdling is a practice which is deserving renewed attention, since in many situations is useful to improve fruit size and to advance harvest. This study seeks to evaluate the effect of manual fruit thinning at intensities of $0,25,50$, and $75 \%$ associated or not to trunk girdling ( $4 \mathrm{~mm}$ wide) on the growth, production and quality of plum cv. Amarelinha. The experiment was carried out at the Universidade Federal do Rio Grande do Sul Experimental Research Station (Southern Brazil), during the growth season of 1995-96 (August - June). Thinning was applied on October 16, 1995, 36 days after full bloom, and girdling seven days after thinning. Thinning decreased total fruit yield proportionally to the applied intensity. Trunk girdling anticipated harvesting, decreased fruit firmness, titratable acidity and increased the ratio total soluble solids: titratable acidity of fruits, but decreased the vigour and vegetative growth of the trees. None of treatments affected significantly the mean fruit weight.
\end{abstract}

Index terms: mean fruit weight, precocity, vegetative growth, vigour.

${ }^{1}$ Aceito para publicação em 3 de março de 1999.

Extraído da Dissertação de Mestrado apresentada pelo primeiro autor à Universidade Federal do Rio Grande do Sul.

${ }^{2}$ Eng. Agr., M.Sc., EMATER-RS, Av. Duque de Caxias, 333, CEP 95975-000 Putinga, RS.

${ }^{3}$ Eng. Agr., Dr., Prof. Assistente, Fac. de Agronomia, UFRGS, Av. Bento Gonçalves, 7712, Caixa Postal 776, CEP 91501-970 Porto Alegre, RS. E-mail: marodin@vortex.ufrgs.br ${ }^{4}$ Eng. Agr., M.Sc., Rua Conde de Porto Alegre, 625/607, Bairro Floresta, CEP 90220-211 Porto Alegre, RS.

${ }^{5}$ Eng. Agr., Ph.D., Prof. Titular, Fac. de Agronomia, UFRGS.

\section{INTRODUÇÃO}

A produção de ameixas com elevado padrão de qualidade, com tamanho, aparência e sabor comercialmente aceitáveis, é fundamental para o êxito comercial de frutos para consumo in natura.

O peso médio de frutos comercialmente aceito para ameixas japonesas varia conforme as condições de mercado e a cultivar. Avaliando o desempenho de ameixeiras durante cinco safras, no município de Veranópolis, RS, Grellmann \& Simonetto (1995) 
obtiveram um peso médio de frutos de $52 \mathrm{~g}$ para a cultivar Amarelinha.

A poda de inverno e o raleio dos frutos são práticas adotadas tradicionalmente na cultura da ameixeira, visando, entre outros efeitos, o aumento do tamanho dos frutos remanescentes e a regularização da produção, evitando as safras alternadas e o esgotamento das plantas. Um procedimento complementar a essas práticas consiste no anelamento do tronco, ou dos ramos, técnica antiga que vem recebendo renovada atenção.

Em alguns países produtores de frutas de caroço, o anelamento tem sido utilizado como prática eficaz para aumentar o tamanho final do fruto, melhorar sua coloração, e antecipar a colheita (Juan et al., 1995).

Noel (1970) comenta que o anelamento consiste em interromper completamente o fluxo de seiva liberiana via floema, seja por uma pequena incisão, ou pela remoção de uma faixa de casca ao redor do tronco ou dos ramos da árvore. Salienta-se que o termo casca é aqui utilizado para designar todos os tecidos externos ao xilema secundário. $\mathrm{O}$ anelamento interrompe temporariamente o fluxo de seiva elaborada em direção às raízes e, desta forma, provoca alterações no balanço endógeno de carboidratos (Allan et al., 1993), fitormônios (Dann et al., 1985; Cutting \& Lyne, 1993) e elementos minerais (Day \& Dejong, 1990). Em resposta ao conjunto de alterações fisiológicas provocadas pelo anelamento, os frutos situados acima da região anelada apresentam seu crescimento estimulado.

Resultados experimentais indicam que o anelamento pode proporcionar efeitos positivos em várias espécies do gênero Prunus, aumentando o tamanho do fruto (North et al., 1988), incrementando a produção e antecipando a maturação (Pérez \& Rodriguez, 1987), melhorando a coloração (Almela et al., 1995) e aumentando o teor de sólidos solúveis nos frutos (Day \& Dejong, 1990).

O presente trabalho teve como objetivo avaliar o efeito de diferentes intensidades de raleio manual de frutos, associadas ou não ao anelamento do tronco, sobre o crescimento, a produção e a qualidade dos frutos da ameixeira japonesa (Prunus salicina Lindley) cv. Amarelinha, nas condições do sul do Brasil.

Pesq. agropec. bras., Brasília, v.34, n.12, p.2211-2217, dez. 1999

\section{MATERIAL E MÉTODOS}

O experimento foi realizado no Setor de Horticultura da Estação Experimental Agronômica da Universidade Federal do Rio Grande do Sul (EEA-UFRGS), município de Eldorado do Sul, Estado do Rio Grande do Sul, situada a $30^{\circ} 5^{\prime} 52^{\prime}$ de latitude sul e $51^{\circ} 39^{\prime} 8^{\prime}$ de longitude oeste, e altitude média de 46 metros. O solo da área experimental é classificado como Podzólico Vermelho-Escuro, de textura franco-argilosa.

Utilizaram-se ameixeiras da cv. Amarelinha (Prunus salicina Lindley), enxertadas sobre pessegueiro (Prunus persica (L.) Batsch), conduzidas em sistema de vaso moderno e com espaçamento de 6,0 m entre linhas e 3,5 m entre plantas. O pomar foi instalado em agosto de 1991, e o experimento iniciou em junho de 1995, quando as plantas apresentavam cerca de quatro anos.

$\mathrm{O}$ trabalho avaliou quatro intensidades de raleio manual de frutos, associadas ou não ao anelamento do tronco. Utilizou-se o delineamento completamente casualizado, com três repetições, sendo cada parcela constituída por uma planta. Os tratamentos, distribuídos num esquema fatorial $4 \times 2$, referentes aos fatores intensidade de raleio manual de frutos (a) e realização, ou não, do anelamento do tronco (b), respectivamente, foram os seguintes: 1) raleio manual de $0 \%$ dos frutinhos; 2 ) raleio manual de $25 \%$ dos frutinhos; 3 ) raleio manual de $50 \%$ dos frutinhos; 4) raleio manual de $75 \%$ dos frutinhos; 5) raleio manual de $0 \%$ dos frutinhos + anelamento do tronco; 6 ) raleio manual de $25 \%$ dos frutinhos + anelamento do tronco; 7) raleio manual de $50 \%$ dos frutinhos + anelamento do tronco; 8) raleio manual de $75 \%$ dos frutinhos + anelamento do tronco.

Objetivando-se controlar a heterogeneidade das parcelas, utilizou-se a técnica de análise de covariância, e em cada planta (parcela) foram coletadas as seguintes covariáveis: número inicial de frutos (colhidos + raleados) e relação número inicial de frutos $/ \mathrm{cm}^{2}$ de secção transversal do tronco a $20 \mathrm{~cm}$ do solo, imediatamente antes da execução do raleio.

A análise estatística, adotada para todas as variáveis, consistiu na análise de variância para o modelo completamente casualizado, com estrutura fatorial para tratamentos. Realizou-se a análise de covariância, quando esta se justificava.

Utilizou-se o teste $\mathrm{F}$ para comparar as médias entre plantas aneladas e não aneladas, e a análise de regressão para detalhar o efeito do raleio na produção, quando este foi significativo. Em todos os casos utilizou-se um nível de significância de 5\%, tanto no teste $\mathrm{F}$ quanto na análise de regressão. 
O raleio de frutos foi executado dia 16 de outubro de 1995, 36 dias após a plena floração, durante o período de lignificação do endocarpo e praticamente ao final do período de queda natural de frutinhos. Realizou-se uma contagem prévia dos frutos em cada planta e, conforme o tratamento, determinou-se o número de frutos a serem raleados em cada uma dessas plantas. O raleio foi realizado manualmente e de forma seletiva, retirando-se preferencialmente os frutos pequenos, defeituosos, mal posicionados ou atacados por pragas ou moléstias.

O anelamento do tronco foi realizado no dia 23 de outubro de 1995, sete dias após a realização do raleio de frutos, aproximadamente a $30 \mathrm{~cm}$ do solo, e com largura de $4 \mathrm{~mm}$. Com o auxílio de um canivete comum, cortou-se a casca do tronco nas bordas de uma fita adesiva até perceber-se uma certa resistência. $\mathrm{O}$ anel de casca, incluindo todos os tecidos externos ao xilema secundário, foi então retirado.

A porcentagem de raleio efetivo de frutos (A) alcançada para cada intensidade de raleio prevista foi obtida através da relação entre o número de frutos raleados $(\mathrm{B})$ e o número total de frutos contidos na planta imediatamente antes do raleio $(\mathrm{C}): \mathrm{A}=\mathrm{B} / \mathrm{C}$ x 100 . O número total de frutos, para cada planta, foi calculado somando-se o número de frutos colhidos ao número de frutos raleados por planta.

Visando determinar o incremento da área de secção transversal do tronco realizaram-se duas medições da circunferência do tronco a $20 \mathrm{~cm}$ do solo, uma em 12/10/95, antes da aplicação dos tratamentos de raleio, e outra em 7/8/1996, antes da poda de inverno. As medidas de circunferência foram transformadas em área de secção transversal do tronco e a variação percentual dessa área, entre as duas datas, foi determinada em cada planta.

Em 15/8/1996, antes da poda de inverno, determinouse em cada planta o comprimento de dez ramos de crescimento do ano situados na periferia da copa. Com os valores obtidos, calculou-se o comprimento médio desses ramos.

Durante a realização das colheitas, em 3, 10 e 17 de janeiro de 1996, os frutos de cada planta foram contados e pesados. Em cada uma das três colheitas, determinou-se: número e peso total de frutos produzidos por planta; peso médio de frutos em relação à produção total; porcentagem de peso dos frutos colhidos em cada uma das três colheitas, em relação ao peso total de frutos colhidos.

$\mathrm{Na}$ segunda colheita, realizou-se uma amostragem de 15 frutos por planta. Os frutos foram levados ao laboratório para análise de firmeza, $\mathrm{pH}$, acidez titulável (AT), sólidos solúveis totais (SST) e relação SST/AT. A firmeza da polpa foi medida com o uso de um penetrômetro com ponta de $11 \mathrm{~mm}$. Em cada um dos 15 frutos da amostra realizou-se a determinação da firmeza da polpa, sendo a leitura realizada na zona equatorial dos frutos, em dois lados opostos, após a retirada da epiderme. A acidez titulável foi avaliada por titulação com hidróxido de sódio $(\mathrm{NaOH}) 0,1 \mathrm{~N}$ de uma amostra de $10 \mathrm{~mL}$ de suco diluída em $90 \mathrm{~mL}$ de água destilada até atingir $\mathrm{pH}$ 8,1, lido no medidor e analisador de $\mathrm{pH}$.

A acidez da polpa dos frutos foi também determinada pela leitura do $\mathrm{pH}$ da polpa liquidificada e filtrada, utilizando-se o medidor e analisador de $\mathrm{pH}$. O teor de SST foi obtido pingando duas a três gotas de suco, retiradas da amostra descongelada e filtrada, em um refratômetro de bancada. A relação sólidos solúveis totais/acidez titulável foi obtida a partir das determinações anteriormente realizadas de sólidos solúveis totais e acidez titulável.

\section{RESULTADOS E DISCUSSÃO}

As intensidades de raleio de frutos previstas no experimento não foram efetivamente alcançadas em nenhum dos tratamentos. Isto evidencia as dificuldades da execução do raleio em intensidades predeterminadas, baseadas em uma contagem prévia dos frutos jovens logo antes da aplicação dos tratamentos de raleio. A contagem dos frutos jovens subestimou o número de frutos nas plantas e levou a intensidades efetivas de raleio sempre inferiores às previstas. As intensidades previstas de 0, 25, 50 e $75 \%$ corresponderam, respectivamente, a $0,23,41$ e $65 \%$ de raleio efetivo de frutos.

Em 15 agosto de 1996, as plantas aneladas apresentavam comprimento médio dos ramos do ano de $63 \mathrm{~cm}$, e as plantas não aneladas, de $79 \mathrm{~cm}$, sendo esta diferença significativa pelo teste $\mathrm{F}$ a $5 \%$ de probabilidade. Esses resultados concordam com os obtidos por Fernandez-Escobar et al. (1987), Pérez \& Rodriguez (1987), Day \& Dejong (1990) e Cutting \& Lyne (1993) em que o anelamento diminuiu o crescimento de ramos em pessegueiros e nectarineiras. Cutting \& Lyne (1993) verificaram que o anelamento em pessegueiros, além de reduzir o crescimento de ramos, promoveu redução nas concentrações de citocininas e giberelinas presentes na seiva do xilema, acima da região anelada. Tais observações dão suporte para a hipótese proposta por Dann et al. (1984), de que a redução do crescimento vegetativo provocada pelo anelamento é o resultado da redução do suprimento de substâncias reguladoras de crescimento produzidas pelas raízes. 
O incremento na área de secção transversal do tronco entre 12 de outubro de 1995 e 7 de agosto de 1996, a $20 \mathrm{~cm}$ do solo, foi de $68 \%$ nas plantas aneladas, e de $82 \%$ nas plantas não aneladas, sendo esta diferença significativa pelo teste $\mathrm{F}$ a $5 \%$ de probabilidade. Este resultado está em conformidade com Dann et al. (1984), que verificaram que o anelamento reduziu o incremento da circunferência do tronco em pessegueiros. Segundo estes autores, o anelamento reduz a capacidade do crescimento secundário em competir com o crescimento dos frutos.

Duas semanas após o anelamento, em 6 de outubro de 1995, a região anelada mostrava sinais de início de cicatrização, com formação de calo a partir das bordas do anel. Constatou-se que, neste momento, quase todas as plantas aneladas apresentavam alguma exsudação de goma na região anelada. Até sete de agosto de 1996, antes da poda de inverno, todas as plantas apresentaram completa cicatrização, com $100 \%$ da região anelada sendo preenchida por tecido de cicatrização.

O número e o peso total de frutos produzidos por planta apresentaram decréscimo com o aumento das intensidades de raleio (Figs. 1 e 2). O aumento de uma unidade percentual na intensidade de raleio prevista representou, para o número total de frutos produzidos, um decréscimo de 3,9 frutos por planta e, para o peso total de frutos produzidos, um decréscimo de 0,202 kg por planta. Este resultado está de acordo com os obtidos por outros pesquisadores que estudaram o raleio de frutos em ameixeiras, em que o mesmo diminuiu a produção total (Ducroquet, 1977).

$\mathrm{O}$ raleio e o anelamento não foram efetivos em aumentar significativamente o peso médio dos frutos nas condições do experimento (Tabela 1). Os resultados obtidos são contraditórios ao trabalho de Ducroquet (1977), em que o raleio de frutos em ameixeiras promoveu aumento no peso médio dos frutos colhidos. A ausência de resposta ao raleio, em relação ao peso médio dos frutos, pode ter ocorrido porque as plantas ajustaram sua própria carga de frutos, por intermédio de quedas naturais anteriores ao raleio, para níveis compatíveis com a sua capacidade de nutrir plenamente os frutos remanescentes. Em todos os tratamentos, o peso médio dos frutos foi superior a $54 \mathrm{~g}$, enquanto que o peso médio de fru- tos encontrado por outros pesquisadores para a cultivar Amerelinha não ultrapassa 52 g (Grellmann \& Simonetto, 1995).

A ausência de efeito do anelamento sobre o peso médio dos frutos não está em conformidade com os resultados obtidos por North et al. (1988), Day \& Dejong (1990), Devilliers et al. (1990) e Almela et al. (1995). Algumas das hipóteses que podem ser levantadas para explicar a ausência de efeito do anelamento sobre o peso médio dos frutos são o

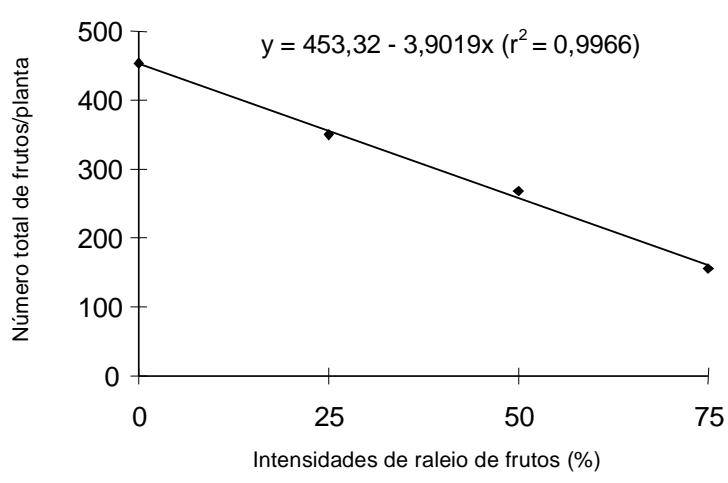

FIG. 1. Número total de frutos produzidos por ameixeiras 'Amarelinha' (Prunus salicina Lindley) em função de intensidades de raleio de frutos. EEA/UFRGS, Eldorado do Sul, RS. 1995-96. (Valores ajustados para o número inicial de frutos por planta).

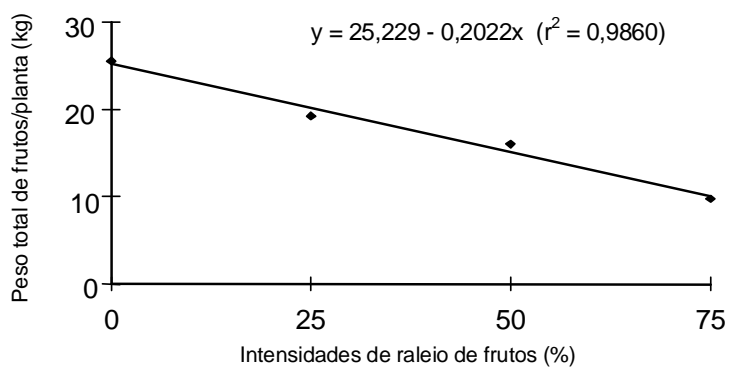

FIG. 2. Peso total de frutos produzidos por ameixeiras 'Amarelinha' (Prunus salicina Lindley) em função de intensidades de raleio de frutos. EEA/UFRGS, Eldorado do Sul, RS. 199596. (Valores ajustados para o número inicial de frutos por planta). 
TABELA 1. Peso médio dos frutos produzidos por ameixeiras 'Amarelinha' (Prunus salicina Lindley) submetidas a quatro intensidades de raleio de frutos, com e sem anelamento do tronco. EEA/UFRGS, Eldorado do Sul, RS. 1995-96'.

\begin{tabular}{cccc}
\hline Intensidade & \multicolumn{3}{c}{ Peso médio dos frutos $(\mathrm{g})$} \\
\cline { 2 - 4 } de raleio & Sem anelamento Com anelamento & Médias \\
\hline $0 \%$ & 59,18 & 54,65 & 56,92 \\
$25 \%$ & 59,78 & 56,55 & 58,17 \\
$50 \%$ & 59,08 & 61,81 & 60,44 \\
$75 \%$ & 59,59 & 64,45 & 62,02 \\
\hline Média $(\mathrm{g})$ & 59,41 & 59,36 & 59,39 \\
\hline
\end{tabular}

1 Valores ajustados para a carga inicial de frutos (covariável), considerada como número de frutos $/ \mathrm{cm}^{2}$ de secção transversal do tronco a $20 \mathrm{~cm}$ do solo, antes do raleio de frutos; não houve efeito significativo de raleio, anelamento ou interação pelo teste $\mathrm{F}$ a $5 \%$ de probabilidade.

suprimento hídrico deficiente, durante o desenvolvimento do fruto, e as características da cultivar. Juan et al. (1995) salientam que o anelamento deve ser executado com o solo em boas condições de umidade e Larue \& Johnson (1988) afirmam que ameixeiras geralmente não respondem ao anelamento, mas não apresentaram resultados experimentais que comprovem esta afirmação. É ainda provável que a cultivar Amarelinha não responda significativamente ao anelamento, no que diz respeito ao aumento de peso dos frutos, já que a resposta a esta prática é dependente não apenas da espécie (Noel, 1970) mas também da cultivar (Fernandez-Escobar et al., 1987).

Apesar da ausência de diferenças significativas no peso médio dos frutos entre os tratamentos, verifica-se que no tocante às plantas não aneladas o peso médio de frutos permaneceu relativamente constante, enquanto para as aneladas identifica-se uma tendência de aumento (não-significativo) no peso médio com o aumento das intensidades de raleio (Tabela 1). Uma hipótese para explicar este comportamento é de que nas plantas não aneladas, o raleio não alterou o peso médio dos frutos provavelmente porque o crescimento dos mesmos teria sido limitado não pelo suprimento de fotoassimilados, mas pela limitada capacidade dos frutos em atuar como "sumidouros", atraindo para si as substâncias necessárias ao seu crescimento. Por outro lado, a tendência de aumento (não-significativo) do peso médio dos frutos nas plantas aneladas, com o aumento das intensidades de raleio, poderia ser atribuída ao aumento da disponibilidade de fotoassimilados para os frutos remanescentes, e à alteração no balanço endógeno de fitormônios; desta forma, nas plantas aneladas e submetidas às maiores intensidades de raleio, os frutos atuaram como potentes "sumidouros", e foram capazes de aproveitar a maior disponibilidade de fotoassimilados, proporcionada pelo intenso raleio de frutos.

A porcentagem do peso de frutos colhidos na primeira colheita aumentou significativamente nas plantas aneladas (Tabela 2). $\mathrm{O}$ anelamento mais que dobrou a porcentagem da produção colhida na primeira colheita. Nas plantas não aneladas a percentagem do peso de frutos colhidos foi de $19,81 \%$, enquanto nas plantas aneladas foi de $42,31 \%$. Estes resultados concordam com os obtidos por FernandezEscobar et al. (1987), Day \& Dejong (1990) e Allan et al. (1993) em pessegueiros e nectarineiras, e Almela et al. (1995) em ameixeiras e outras frutíferas de caroço. Segundo Juan et al. (1995), a data em que os frutos alcançam seu estado ótimo para a colheita é antecipada com o emprego do anelamento, já que o tamanho e a coloração do fruto são os parâmetros que decidem o momento da colheita, e que ambos tendem a ser melhorados por ação do anelamento. $\mathrm{O}$ anelamento diminuiu em mais de $50 \%$ a porcentagem do peso de frutos colhidos na terceira colheita. Tais resultados concordam com os obtidos por Allan et al. (1993) e Fernandez-Escobar et al. (1987), em que a porcentagem da produção colhida na última colheita foi significativamente diminuída em pessegueiros e nectarineiras anelados.

Os resultados obtidos sugerem que o anelamento, apesar de não ter afetado significativamente o peso médio do fruto, acelerou seu crescimento e fez com que a maturação fosse antecipada, em relação aos frutos de plantas não aneladas.

Os frutos das plantas aneladas apresentaram menor firmeza de polpa, menor acidez titulável e maior relação SST/AT em relação aos frutos provenientes das plantas não aneladas. Além disso, os frutos das plantas aneladas apresentaram um teor de sólidos solúveis totais de $13,93 \%$, contra $13,70 \%$ dos frutos de plantas não aneladas, embora esta diferença não tenha sido estatisticamente significativa (Tabela 3). Esses resultados confirmam os estudos de Pérez \& 
TABELA 2. Porcentagem de frutos colhidos na primeira, segunda e terceira colheitas de ameixeiras 'Amarelinha' (Prunus salicina Lindley), com e sem anelamento do tronco. EEA/UFRGS, Eldorado do Sul, RS. 1995-96'.

\begin{tabular}{|c|c|c|c|}
\hline \multirow[t]{2}{*}{ Tratamento } & \multicolumn{3}{|c|}{ Porcentagem do peso de frutos colhidos } \\
\hline & $1^{\text {a }}$ colheita $^{2}$ & $2^{-a}$ colheita & $3^{-a}$ colheita \\
\hline Plantas não aneladas & $19,81 b$ & $51,18 \mathrm{a}$ & $29,01 \mathrm{a}$ \\
\hline Plantas aneladas & $42,31 \mathrm{a}$ & $44,69 \mathrm{a}$ & $13,00 \mathrm{~b}$ \\
\hline \multicolumn{4}{|c|}{$\begin{array}{l}{ }^{1} \text { Médias seguidas da mesma letra na vertical não diferem significativa- } \\
\text { mente pelo teste } \mathrm{F} \text { a } 5 \% \text { de probabilidade. } \\
2 \text { Valores ajustados para a carga inicial de frutos, considerada como núme- } \\
\text { ro de frutos } / \mathrm{cm}^{2} \text { de secção transversal do tronco a } 20 \mathrm{~cm} \text { do solo, antes } \\
\text { do raleio de frutos. }\end{array}$} \\
\hline
\end{tabular}

TABELA3. Características físico-químicas dos frutos de ameixeiras 'Amarelinha' (Prunus salicina Lindley), com e sem anelamento do tronco. EEA/UFRGS, Eldorado do Sul, RS. 1995-961.

\begin{tabular}{lrrrrr}
\hline Tratamento & $\begin{array}{r}\text { Firmeza } \\
(\mathrm{kg})\end{array}$ & $\begin{array}{r}\text { SST } \\
(\%)\end{array}$ & $\begin{array}{c}\text { Acidez } \\
(\mathrm{Ac})(\%)\end{array}$ & $\mathrm{pH}$ & $\begin{array}{c}\text { Relação } \\
\text { SST/Ac }\end{array}$ \\
\hline Plantas não aneladas $10,51 \mathrm{a}$ & $13,70 \mathrm{a}$ & $0,81 \mathrm{a}$ & $3,54 \mathrm{a}$ & $17,01 \mathrm{~b}$ \\
Plantas aneladas & $9,72 \mathrm{~b}$ & $13,93 \mathrm{a}$ & $0,73 \mathrm{~b}$ & $3,53 \mathrm{a}$ & $19,16 \mathrm{a}$ \\
\hline
\end{tabular}

Rodriguez (1987), North et al. (1988) e Almela et al. (1995). De uma forma geral, os resultados indicam que no início do período de colheita os frutos de plantas aneladas estavam em um estádio de maturação mais avançado que os frutos de plantas não aneladas, confirmando que o anelamento promoveu uma antecipação da maturação dos frutos e, consequientemente, da colheita.

$\mathrm{O}$ raleio de frutos não afetou significativamente nenhuma das características físico-químicas da polpa dos frutos.

\section{CONCLUSÕES}

1. O raleio manual de frutos, aos 36 dias após a plena floração, reduz a produção em ameixeiras cultivar Amarelinha proporcionalmente à intensidade de raleio aplicada.
2. O raleio manual de frutos, aos 36 dias após a plena floração, e o anelamento do tronco, aos 43 dias após a plena floração, não alteram o peso médio dos frutos em ameixeiras cultivar Amarelinha.

3. O anelamento do tronco, aos 43 dias após a plena floração, antecipa a maturação e a colheita dos frutos.

4. O anelamento do tronco altera as características físico-químicas da polpa dos frutos, diminuindo a firmeza e a acidez titulável e aumentando a relação sólidos solúveis totais/acidez titulável.

5. O anelamento do tronco diminui o vigor e o crescimento vegetativo das plantas.

\section{REFERÊNCIAS}

ALLAN, P.; GEORGE, A.P.; NISSEN, R.J.; RASMUSSEN, T.S. Effects of girdling time on growth, yield, and fruit maturity of the low chill peach cultivar flordaprince. Australian Journal of Experimental Agriculture, Melbourne, v.33, n.6, p.781-785, 1993.

ALMELA, V.; JUAN, M.; CARREGUÍ, M.A.; MEDINA, F.; ANDREU, I.; AGUSTÍ, M. La incisión anular como técnica de estímulo del desarrollo de los frutos de hueso. Fruticultura Profesional, Barcelona, n.69, p.16-26, 1995.

CUTTING, J.G.M.; LYNE, M.C. Girdling and the reduction in shoot xylem sap concentrations of cytokinins and gibberellins in peach. Journal of Horticultural Science, Ashford, v.68, n.4, p.619626, 1993.

DANN, I.R.; JERIE, P.H.; CHALMERS, D.J. Short term changes in cambial growth and endogenous IAA concentrations in relation to phloem girdling of peach, Prunus persica (L.) Batsch. Australian Journal of Plant Physiology, Melbourne, v.12, p.395-402, 1985.

DANN, I.R.; WILDES, R.A.; CHALMERS, D.J. Effects of limb girdling on growth and development of competing fruit and vegetative tissues of peach trees. Australian Journal of Plant Physiology, Melbourne, v.11, p.49-58, 1984.

DAY, K.R.; DEJONG, T.M. Girdling of early season 'Mayfire' nectarine trees. Journal of Horticultural Science, Ashford, v.65, n.5, p.529-534, 1990. 
DEVILLIERS, H.; CUTTING, J.G.M.; JACOBS, G.; STRYDOM, D.K. The effect of girdling on fruit growth and internal quality of Culemborg peach. Journal of Horticultural Science, Ashford, v.65, p.151-155, 1990.

DUCROQUET, J.H.J. Intensidade de raleio manual em ameixeira japonesa (Prunus salicina, Lindley) cultivar Santa Rosa. Florianópolis: EMPASC, 1977. 9p. (Indicação de Pesquisa, n. 22).

FERNANDEZ-ESCOBAR, R.; MARTIN, R.; LOPEZRIVARES, P.; SUAREZ, M.P. Girdling as a means of increasing fruit size and earliness in peach and nectarine cultivars. Journal of Horticultural Science, Ashford, v.62, n.4, p.463-468, 1987.

GRELLMANN, E.O.; SIMONETTO, P.R. Dados de fenologia e produção de cultivares de ameixeira (Prunus salicina Lindl.). Porto Alegre: FEPAGRO, 1995. 11p. (Circular técnica, 3).

JUAN, M.; MEDINA, F.; ALMELA, V.; AGUSTÍ, M. El rayado de ramas como técnica para mejorar la calidad de los frutos de hueso. Valencia: Generalitat Valenciana, Conselleria de agricultura y medio ambiente, $1995.17 \mathrm{p}$.

LARUE, J.M.; JOHNSON, S. Girdling fresh shipping peach and nectarine trees, California. In: CHILDERS, N.F.; SHERMAN, W.B. (Eds.).The peach: world cultivars to marketing. 4.ed. Gainesville: Horticultural Publications, 1988. p.540-545.

NOEL, A.R.A. The girdled tree. The Botanical Review, New York, v.36, n.2, p.162-195, 1970

NORTH, M.; STADLER, J.D.; DEVILLIERS, H. Effect of cyanamide and girdling on yield, fruit size and quality of De Wet peach. South African Journal of Plant and Soil, Pretoria, v.5, n.4, p.224-226, 1988.

PÉREZ, B.H.; RODRIGUEZ, A.J. Efecto del anillado en el rendimiento y calidad del fruto de árboles de durazno (Prunus persica L.) bajo un sistema de producción intensiva. Agrociencia, Chapingo, n.68 p.63-73, 1987. 